\title{
Mealiness assessment in apples and peaches using MRI techniques
}

\author{
P. Barreiro ${ }^{a}$, C. Ortiz ${ }^{\mathrm{a}, *}$, M. Ruiz-Altisent ${ }^{\mathrm{a}}$, J. Ruiz-Cabello ${ }^{\mathrm{b}}$, M.E. Fernández-Valle ${ }^{\mathrm{b}}$ \\ I. Recasens ${ }^{\mathrm{c}}, \mathrm{M}$. Asensio ${ }^{\mathrm{c}}$

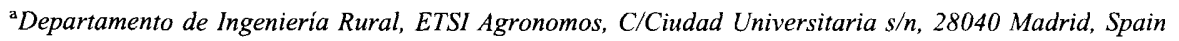 \\ ${ }^{\mathrm{b}}$ Unidad de RMN, UCM, Madrid, Spain \\ 'Postharvest Dept. CeRTA, Centro UdL-IRTA, Lerida, Spain
}

Received 28 May 2000; accepted 11 July 2000

\begin{abstract}
Mealiness (woolliness in peaches) is a negative attribute of sensory texture that combines the sensation of a desegregated tissue with the sensation of lack of juiciness. In this study, 24 apples cv. Top Red and 8 peaches cv. Maycrest, submitted to 3 and 2 different storage conditions respectively have been tested by mechanical and MRI techniques to assess mealiness. With this study, the results obtained on apples in a previous work have been validated using mathematical features from the histograms of the T2 maps: more skewed and the presence of a tail in mealy apples, similar to internal breakdown. In peaches, MRI techniques can also be used to identify woolly fruits. Not all the changes found in the histograms of woolly peaches are similar from those observed in mealy apples pointing to a different underlying physiological change in both disorders. (C) 2000 Elsevier Science Inc. All rights reserved.
\end{abstract}

Keywords: Magnetic resonance imaging; Apple; Peach; Mealiness; Woolliness; Internal breakdown

\section{Introduction}

Mealiness is a negative attribute of sensory texture that combines the sensation of a desegregated tissue with the sensation of lack of juiciness [1]. Peach mealy textures are also known as woolliness and leatheriness. In woolly textures, the lack of juiciness is caused by gel structures that retain the water molecules [2] while the lack of juiciness in mealy apples is due to the lack of rupture of the cells which separate due to the weakness of the middle lamella [3].

Within a wide project devoted to the study of mealiness in fruits, consumers perception and means for detection, several instrumental procedures have been tested for mealiness assessment [1]. In this sense, our laboratory has focused its aims in a first stage on performing instrumental tests for assessing some textural descriptors as crispiness, hardness and juiciness. The results obtained within these tests have shown to correlate well with the sensory measurements in apples [1] but also have succeeded when trying to generate several texture degradation levels on apples and peaches from which mealiness appears to be the last stage

\footnotetext{
* Corresponding author.
}

$[4,5]$. In these studies, it has also been confirmed that mealiness does not appear for all fruits at the same time and therefore it is essential to assess mealiness on individual fruits. Thus, the use of non destructive techniques for a precise assessment of mealiness onset and its monitoring is of prime importance.

The MRI, together with X-Ray imaging techniques are the most extended techniques capable of evaluating global internal quality in a non-destructive way [6]. Magnetic Resonance Imaging (MRI) makes use of the magnetic properties that some atomic nuclei have, especially hydrogen nuclei from water molecules. When placed in a magnetic field (such as in an MR instrument), the natural magnetic fields of the hydrogen nuclei re-orient themselves along the strong magnetic field of the scanner. This orientation may be perturbed by exciting those nuclei with a burst of electromagnetic energy ( $\mathrm{rf}$ pulse). As these excited nuclei realign themselves with the scanner's magnetic field, they emit a radiofrequency signal that can be detected by a receiver coil. The nuclei emit different signals depending on their surroundings. The contrast between various structures would be poor since tissues do not differ substantially in water content. However, there are numerous properties of the tissue water which can be exploited to provide contrast 
and these can be used to obtain other useful information. The MRI imaging technique has been proposed to assess internal injury due to field conditions: water-core in apples [6], and storage treatments as: chilling injury in persimmons [7] and internal breakdown in melons [8].

Previous work on mealiness assessment in apples and peaches through mechanical tests [4,5] and in apples through MRI technique has already been conducted by us [10]. The most important MRI feature extracted is a change in the histograms of mealy apples (more skewed and less symmetric when compared to non-mealy apples) which is also appreciated for apples with internal breakdown.

\section{Objectives}

The work conducted within this paper is devoted to the validation of previous results in MRI on apples and to check the feasibility of those features in peaches. The obtention of mathematical indicators for the histogram features will be the final goal of this study.

\section{Materials and methods}

\subsection{Selection of fruits}

24 apple fruits corresponding to the variety "Top-Red" have been tested under mechanical and MRI imaging techniques. These fruits correspond to selected samples of a wide experiment for mealiness assessment on 160 fruits. Eight apples correspond to a small sample of fruits harvested under commercial conditions and stored under controlled atmosphere in commercial storage chambers for a 6 months period. The rest of 16 apples correspond to two small samples of fruits $(8+8)$ stored under $+0.5^{\circ} \mathrm{C}$ in commercial cold chambers for the same period. They correspond to early and late dates of harvest respectively.

8 peaches corresponding to the variety "Maycrest" have been tested under mechanical and MRI imaging techniques. As in the case of apples, these fruits belong to small samples of a wide experiment of 270 peaches studying the effect of field and storage conditions on the onset of woolliness. 4 peaches correspond to low maturity stage at harvest combined with 3 weeks of storage at $1^{\circ} \mathrm{C}$ (treatment $\mathrm{A}$, expected to be non woolly) while the other 4 fruits correspond to higher maturity stage at harvest combined with 3 weeks of storage at $5^{\circ} \mathrm{C}$ (treatment $\mathrm{B}$, expected to be woolly).

\subsection{Magnetic resonance imaging}

MRI experiments were performed on a Bruker Biospec 47/40 (Ettlingen, Germany) spectrometer equipped with actively shielded imaging gradients capable of reaching 100 $\mathrm{mT} / \mathrm{m}$ along all axes. The bore size of the magnet is $40 \mathrm{~cm}$, but with gradient stack in place, the bore is reduced to 26 $\mathrm{cm}$. A home-built high pass birdcage coil $(N=8)$ with an inner diameter of $10.4 \mathrm{~cm}$ and a length of $14.0 \mathrm{~cm}$ was constructed to adapt the coil to the maximum size of our apples.

Apples were imaged as $128 \times 128$ matrices using the standard two dimensional spin echo sequence. Peaches were imaged as $64 \times 64$ matrices using also the standard two dimensional spin echo sequence. 1 slice and 20 echoes were collected with different echo time, TE, of $9.5 \mathrm{~ms}$, and a fixed repetition time of $3000 \mathrm{~ms}$. Other acquisition parameters were a $5 \mathrm{~mm}$ slice thickness and a $10 \mathrm{~cm}$ field of view (FOV). Pulse gains, attenuator and shimming settings were previously adjusted for a $8 \mathrm{~cm}$ sphere filled with dopped water (copper sulfate, $1 \% \mathrm{w} / \mathrm{w}$ ) and were held constant along the total experiment, in which several apples were imaged under these conditions. Field homogeneity was tested as the lack of change in the images of the spherical phantom before and after the apples recording. For comparison, all images were reconstructed with identical scale factor. The magnitude of these multiecho images was fitted on a pixel by pixel basis using a two parameter (T2 and the signal intensity at equilibrium) monoexponential function without baseline, using the standard Bruker imaging Fit Package, which uses the Levenberg-Marquart criterion for $\chi^{2}$ minimization operating on a Silicon Graphics Indy computer. The software package allows to choose a threshold to remove those pixels with low signal to noise ratio, in such a way that T2 maps of all samples were obtained discharging pixels (previous to the fitting) under the $15 \%$ of the maximum signal intensity (this value was found correct to get rid of background pixels). Measurements with the phantom in the apple experiment (average T2 value of $33.46 \mathrm{~ms}$ ) lead to a spatial variability in the $\mathrm{T} 2$ values assessment of \pm $0.44 \%$ and $\pm 3.88 \%$ of temporal variation. Histograms were attained by removing those pixels with $\mathrm{T} 2$ values (digitized at four bits) equal to zero (those pixels which did not fit corresponding to core and background areas).

Several mathematical features were obtained:

- from global T2 maps (also disregarding those pixels corresponding to the background or the core): Average, Standard deviation, Maximum, Minimum,

- from T2 histograms: lower quartil (T2 lower limit containing $25 \%$ of pixels of the histogram), upper quartil (T2 upper limit containing $25 \%$ of pixels of the histogram), T2 mode (most frequent values), mode height (number of pixels with $\mathrm{T} 2$ value equal to the mode), interquartil range (difference between upper and lower quartils), $1^{\text {st }}$ shape coefficient (mode height/interquartil range), $2^{\text {nd }}$ shape coefficient $\left(0,5^{*}\right.$ number of pixels of the histogram/interquartil range), number of pixels below $35 \mathrm{~ms}$. Besides these parameters based on previous knowledge on the application of MRI to apple, in peaches some new parameters were studied: $3^{\text {rd }}$ shape coefficient (T2 


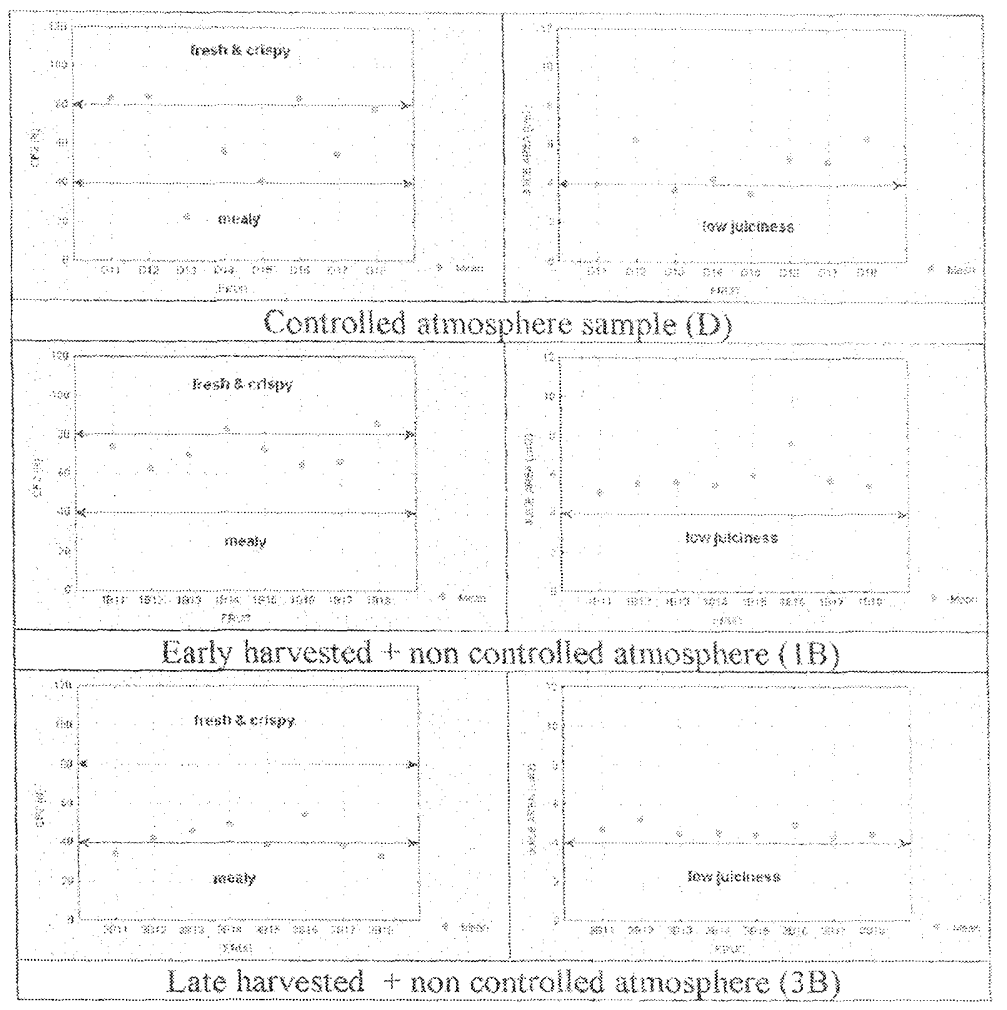

Fig. 1. Identification of fresh \& crispy, intermediate and mealy fruits by means of mechanical test ( 8 fruits per sample)

mode -lower quartil), and number of pixels below 60 ms.

\subsection{Mechanical and chemical tests}

The mechanical tests carried out on the samples can be summarized as:

3.3.1. Magness-Taylor penetration test It was carried out with a Texture Analyser XT2 on entire fruits. MagnessTaylor flesh penetration test was performed for a $8 \mathrm{~mm}$ diameter rod. A maximum penetration of $8 \mathrm{~mm}$ was applied at $20 \mathrm{~mm} / \mathrm{min}$ speed rate. The maximum penetration force was registered and will be used as Magness-Taylor firmness. One repetition was performed per fruit.

3.3.2. Confined compression test It was carried out with the same Texture machine on cylindrical probes $(1.7 \mathrm{~cm}$ height and $1.7 \mathrm{~cm}$ of diameter for apples and $1.4 \mathrm{~cm}$ height and 1.4 $\mathrm{cm}$ of diameter. For peaches). Probes were confined in a disc of the probe height, with a hole also of the same diameter as the fruit probe. A maximum deformation of 2.5 $\mathrm{mm}$ for apples and $2.0 \mathrm{~mm}$ for peaches was applied at 20 $\mathrm{mm} / \mathrm{min}$ speed rate. The rod used in this test had a diameter of $15.3 \mathrm{~mm}$ for apples and $12,5 \mathrm{~mm}$ for peaches in order to avoid rod/disc contacts during compression. Deformation was immediately removed at the same speed rate; three repetition was made per fruit; 3 repetitions per fruit were performed for apple while only 1 repetition per fruit was made for peach. The following parameters were registered through this tests: Force/deformation ratio within the elastic behavior $(\mathrm{N} / \mathrm{mm}$, this magnitude will be used as compression hardness), and the Juice area $\left(\mathrm{mm}^{2}\right)$ of the spot accumulated in a filter paper placed underneath the probe during the test (this magnitude will be used as compression juiciness).

3.3.3. Shear rupture test This test was only applied on peaches. It is carried out with a special device formed by a metacrilate cubic box $(8 \mathrm{~cm}$ wide), with a prismatic hole in the center $(3 \times 8 \times 0,7 \mathrm{~cm})$. Inside this hole a longer prism of $3 \times 9 \times 0.7 \mathrm{~cm}$ can be placed, and slid. Both the rectangular part and the cube have a transversal cylindrical hole where a fruit probe is placed in order to be cut by the rectangular element when pushed by the Texture machine. Two cylindrical nylon pieces joint together by a rubber band compress the probe to maintain it in a fixed position during the test. This test was carried out on probes of $1.4 \mathrm{~cm}$ diameter and $2.0 \mathrm{~cm}$ height. In this test an increasing deformation was applied at a $20 \mathrm{~mm} / \mathrm{min}$ speed rate until probe rupture is achieved; one repetition was carried out per peach. The maximum force at the shear rupture point was registered, which will be used as shear crispness $(\mathrm{N})$.

As chemical tests: the solid soluble content ( $\left.{ }^{\circ} \mathrm{BRIX}\right)$ using a digital refractometer (PR-101 ATAGO, and the titratable or total acidity (meq/l) by means of $\mathrm{NaOH} 0.1 \mathrm{~N}$ and phenolphthalein indicator were measured. 
T2 histograms

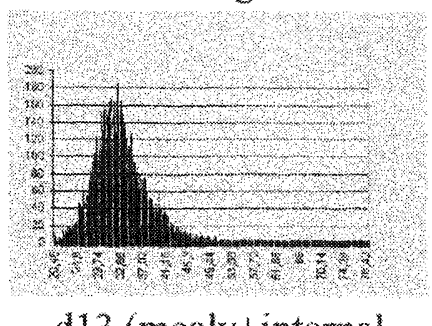

d13 (mealy+internal breakdown)

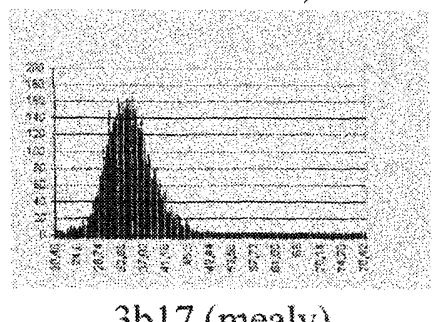

3 b17 (mealy)

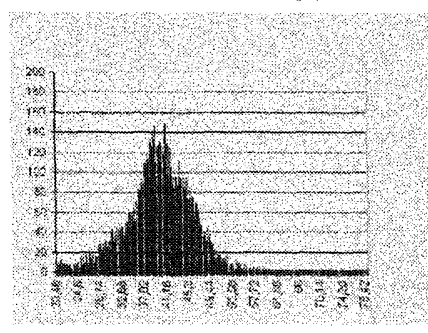

3b12 (intermediate)

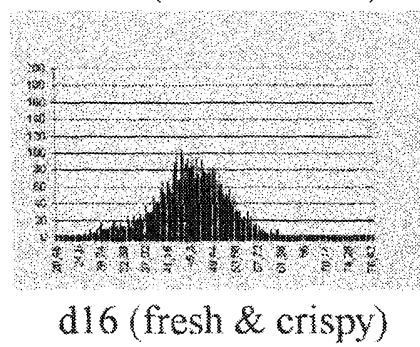

T2 images
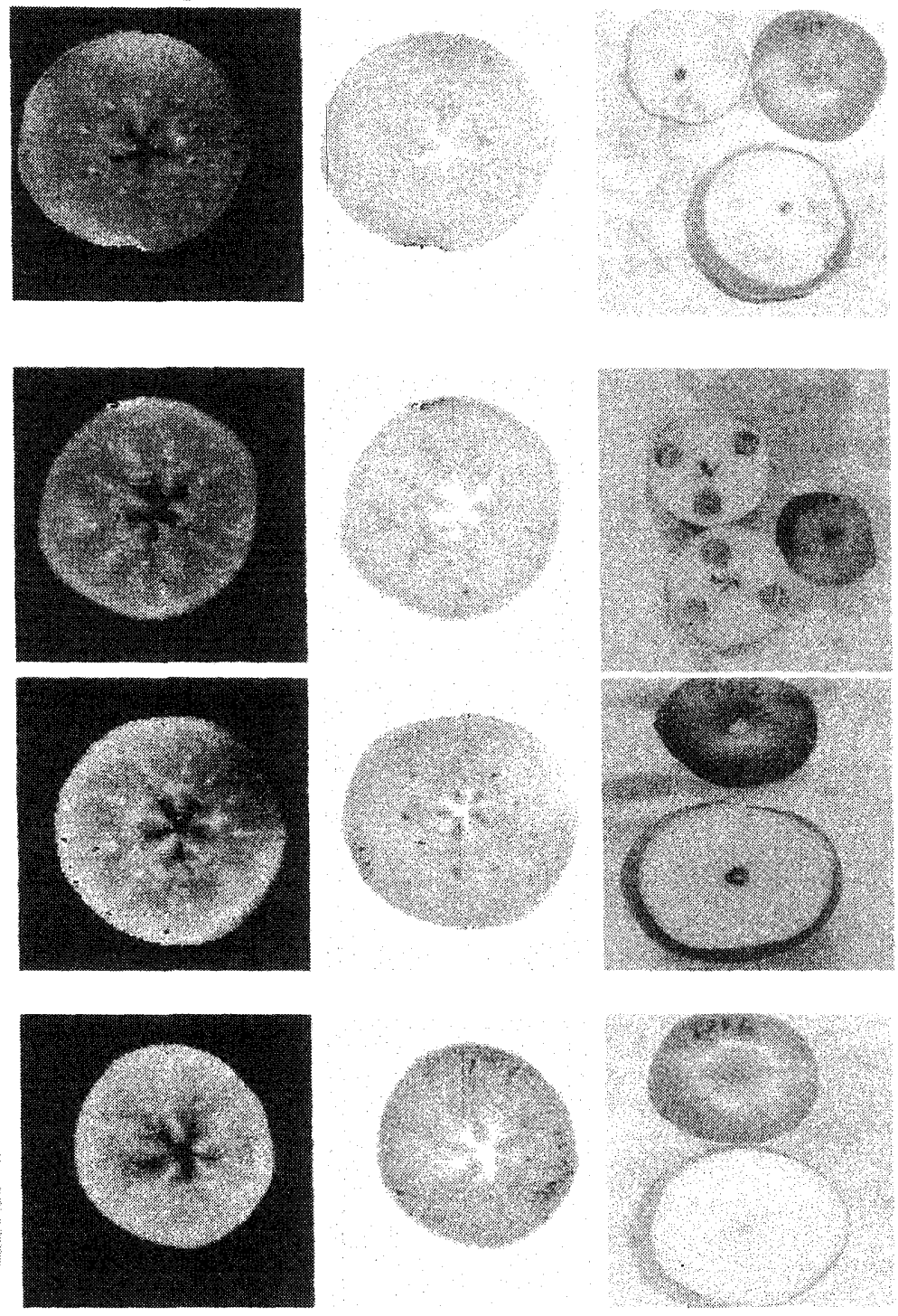

Fig. 2. Examples of 2 mealy apples (first and second line, the first one also showing internal breakdown) and intermediate and fresh fruits (third and fourth line respectively).

\section{Results}

\subsection{General overview of the samples}

The apples used within this study covered a wider range of textural variation (Magness-Taylor firmness between $34 \mathrm{~N}-10 \mathrm{~N}$ approx.) than the fruits managed in the previous work [10] (Magness-Taylor firmness between 20-12N approx.), though the lower end (related to mealy textures) of the textural variation is similar in both cases. The decrease in the Magness-Taylor firmness under cold storage from harvest (duplo samples corresponding to the wide experiment) until the performance of the MRI test is maximum for the late harvested apples (from $33.95 \mathrm{~N}$ to $16,70 \mathrm{~N}$ ) when compared to early harvested (from $39.45 \mathrm{~N}$ to $26.20 \mathrm{~N}$ ) or apples under controlled atmosphere conditions (from $36.34 \mathrm{~N}$ to $20.47 \mathrm{~N}$ ). Samples under non controlled atmosphere show a decrease in chemical components (soluble solids and acidity) while soluble solids under controlled atmosphere increase from 11.45 to $15.24{ }^{\circ} \mathrm{BRIX}$ (also observed in the previous study [10]. In the case of controlled atmosphere samples, acidity also decreases during storage (45\% decrease approx) though this decrease is lower than under non controlled atmosphere conditions $(70 \%$ decrease approx.).

The peaches used for this study were picked in 2 different ripeness stages (Magness Taylor firmness corresponding to duplo samples at harvest of $41.03 \mathrm{~N}$ and $27.12 \mathrm{~N}$ respec- 

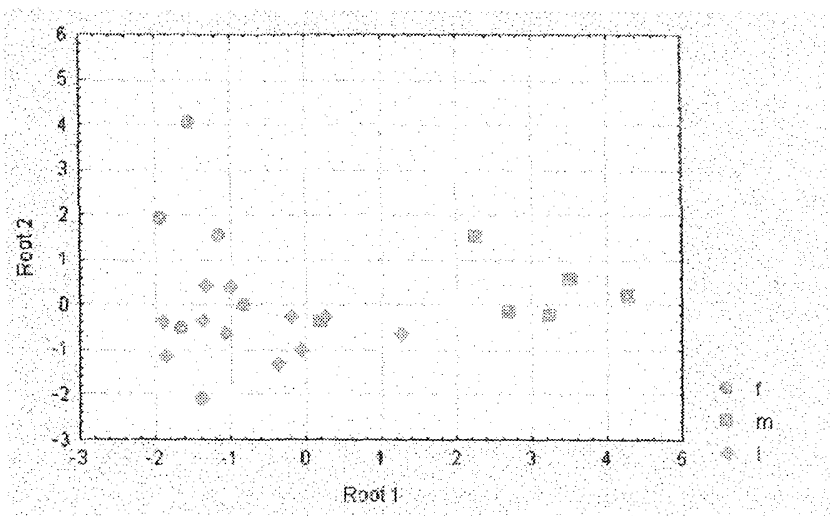

$\begin{array}{ccc} & \text { Root1 } & \text { Root 2 } \\ \text { Shapel } & 0.66 & -0.26 \\ \text { Max. T2 } & -0.11 & 0.96 \\ \text { Pixels<35 } & 0.66 & -0.12 \\ \text { Upper Quart. } & -0.60 & 0.46 \\ \text { Mode Height } & 0.56 & -0.43 \\ \text { T2 STD } & -0.44 & 0.33\end{array}$

Fig. 3. Use of MRI features in apples to discriminate between fresh, intermediate and mealy fruits $(f=$ fresh; $m=$ mealy; $i=$ intermediate $)$

tively). As explained, the less ripe sample was submitted to 3 weeks of cold storage under $1{ }^{\circ} \mathrm{C}$ (expected to be non mealy) decreasing its average Magness-Taylor firmness down to $24.63 \mathrm{~N}$. The most ripe sample at harvest which was submitted to 3 weeks under $5^{\circ} \mathrm{C}$ (expected to be mealy) decreased its average Magness-Taylor firmness down to $3.95 \mathrm{~N}$. No clear variation between ripeness stages at harvest or under cold storage are found for the soluble solid content. Total acidity varied in the less ripe sample submitted to 3 weeks cold storage under $1^{\circ}$ from $165.93 \mathrm{meq} / \mathrm{l}$ (duplo sample at harvest) to $126.25 \mathrm{meq} / 1$, while it varied from $126.4 \mathrm{meq} / 1$ (duplo sample at harvest) to $91.58 \mathrm{meq} / 1$ in the most ripe sample submitted to 3 weeks of storage under $5^{\circ} \mathrm{C}$.

\subsection{Identification of mealy fruits by mechanical means}

The development of an instrumental mealiness scale [5] allows to identificate mealy apples from the results obtained in the confined compression test (see Fig. 1). Apples showing an average compression resistance (CF2) equal or lower to $40 \mathrm{~N}$ are labeled as mealy. High mealiness stage is considered if low juiciness (compression juiciness below 4 $\mathrm{cm}^{2}$ ) combines with this dissagregated texture (CF2 $\left.\leq 40 \mathrm{~N}\right)$. The above mentioned study also allows to identify apples with $C F 2 \geq 80 \mathrm{~N}$ as to be very fresh and crispy (see contribution 98-f-074 to AgEng98). The classification of fruits into fresh $\&$ crispy, intermediate (non crispy but non mealy) and mealy indicates that the controlled atmosphere sample is the most variable with fruits within all three categories (3 fresh, 3 intermediate, 2 medium). Late date of harvest combined with non-controlled atmosphere leads to the highest number of mealy fruits ( 4 intermediate, 4 medium) while non of the early harvested apples under non controlled atmosphere conditions were identified as mealy ( 2 fresh, 6 intermediate).

To identify woolly peaches a similar procedure has been used [4]. Those peaches with Shear resistance (instrumental crispness) lower than $30 \mathrm{~N}$, confined compression slope (instrumental hardness) lower than $14 \mathrm{~N} / \mathrm{mm}$ and compression juiciness lower than $3,5 \mathrm{~cm} 2$ were classified as woolly (lack of crispness, of hardness and of juiciness). 3 out of 4 peaches were classified as woolly within the sample kept under $5^{\circ} \mathrm{C}$ (treatment $\mathrm{A}$ ) while non of the peaches held under $1^{\circ} \mathrm{C}$ (treatment B)were classified as woolly.

In both experiments (apples and peaches) the identification of mealy/woolly fruits by mechanical means was also corroborated by a sensory assessment of the researchers.

\subsection{Extraction of features within the MRI images for mealiness assessment}

Fig. 2 shows T2 maps of apples: 2 mealy apples (the first one also showing internal breakdown), and examples of intermediate and fresh \& crispy apples; all T2 maps (original $\mathrm{T} 2$ data digitized in 4 bytes) are visualized in the range $20-80 \mathrm{~ms}$ to enhance differences. The first column in Fig. 3 shows the histograms corresponding to the T2 maps (second column). The third column shows the negative image of the T2 map and the forth column a photograph of the halved fruits. As expected the histogram of mealy and internal breakdown apples are more skewed than the histogram of fresh \& crispy fruits. The high similarity between the histograms of mealy and internal breakdown apples, and the fact that all apples found with internal browning (d13 \& d15) where the most mealy ones would again point to internal breakdown as being the last stage of texture degradation after mealiness as indicated in our previous study [10]. 


\section{T2 images}

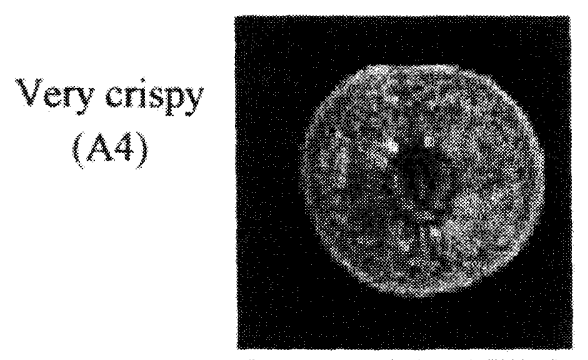

Non crispy
but non
woolly (A1)

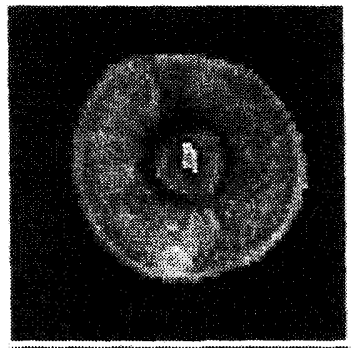

Woolly
(B2)
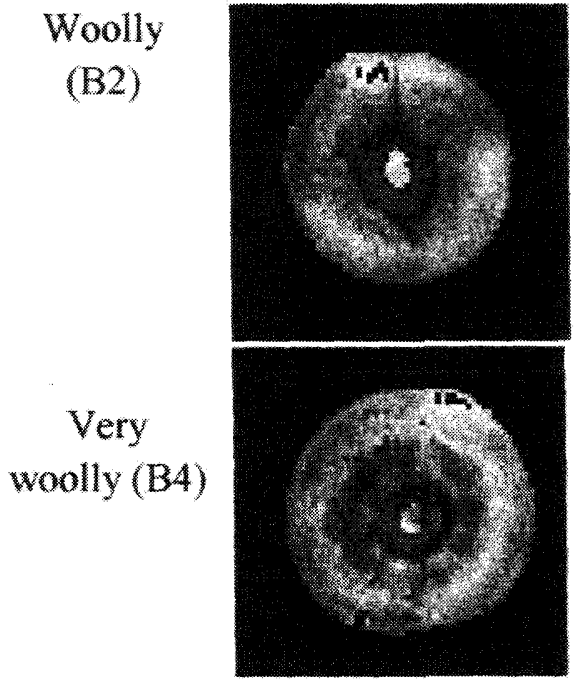

T2 histograms
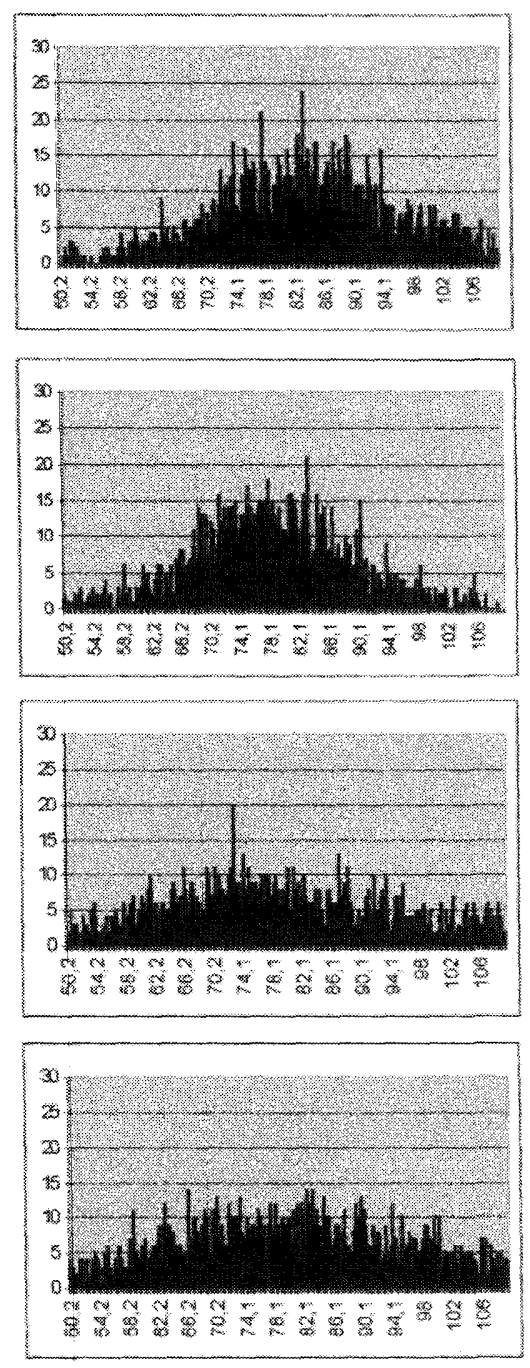

Fig. 4. Examples of a very crispy, a non crispy but not woolly, a woolly and a very woolly peaches T2 maps and the histogram of original $\mathrm{T} 2$ maps.

The classification of apples into fresh \& crispy, intermediate and mealy has been used to check the relationship of the textural categories with the MRI features through ANOVA analysis. The parameters showing the highest significance level correspond as expected to the histogram features: Shape $1(\mathrm{~F}=13.87)$, Pixels $<35 \mathrm{~ms}(\mathrm{~F}=13.25)$, Shape $2(F=12.61)$, Upper quartil $(F=12.34)$, Mode height $(F=10.86)$, Lower quartil $(F=10.08)$, Pixels $<30$ $\mathrm{ms}(\mathrm{F}=9.32)$, Interquartil range $(\mathrm{F}=8.29)$ and mode $(\mathrm{F}=$ 4.79). All MRI features have been used in a stepwise discriminant analysis (see Fig. 3). Using Shape 1, Maximum $\mathrm{T} 2, \mathrm{~N}^{\circ}$ pixels $<35$, Upper quartil, Mode height, and $\mathrm{T} 2$ Standard deviation allows $87.5 \%$ of well classified observations. This shows that features extracted from the histograms are relevant on their own to segregate crispy and mealy apples.

Fig. 4 shows T2 maps and histograms of several peaches: crispy, intermediate (non crispy but non woolly), woolly and very woolly; all T2 maps (original T2 data digitized in 4 bytes) are visualized in the range $37-160 \mathrm{~ms}$ to enhance differences. When comparing T2 maps between peaches and apples, variations in the histograms are found. An increase in the number of pixels below $60 \mathrm{~ms}$ is found for woolly peaches $(120-173$ pixels) when compared to non woolly peaches (31-79 pixels), which was also found for apples as the number of pixels in the lower T2 ranges ( $<30$ $\mathrm{ms}$ and $<35 \mathrm{~ms}$ ) increased for mealy when compared to crispy apples. This fact is not obvious by visual appreciation of the images and therefore the extraction of mathematical indicators is advisable. The changes in the shape of the histograms of woolly peaches are different from those of mealy apples. Mealy apples turned to more skewed histograms than crispy apples, while the histograms of woolly peaches turned to be more flat loosing the Gaussian appear- 
ance. This fact could be understood as a different physiological change underlying mealiness and woolliness.

\section{Conclusions}

The MRI features extracted on mealiness assessment in apples in a previous work have been validated as mealy fruits show a more skewed histogram in relation to non mealy fruits. Stepwise discriminant analysis has been used on the basis of MRI features to segregate between fresh, intermediate and mealy fruits with $87.5 \%$ of well classified observations.

It is confirmed the association between internal breakdown and mealiness as both types of fruits show the same histogram shape and all internal breakdown fruits are identified as mealy through confined compression test.

In peaches, MRI techniques can also be used to discriminate between woolly and non woolly fruits. Not all the changes found in the histograms of woolly peaches are similar from those observed in mealy apples pointing to a different underlying physiological change in both disorders.

\section{Acknowledgments}

PBE and MRA acknowledges to the EC Project FAIR CT960302. MEFV and JRC thanks the Spanish Comision Interministerial de Ciencia y Tecnologia (CICYT) for funding (PB91-0368 and BIO97-0543).

\section{References}

[1] Barreiro P, Ruiz-Altisent M, Ortiz C, De Smedt V, Schotte S, Bhanji $\mathrm{Z}$, Wakeling $\mathrm{Z}$. Comparison between sensorial and instrumental measurements for mealiness assessment in apples. A collaborative test. Accepted for publication in the J Texture Studies Vol 29(5); 1998.

[2] Kailasapathy K, Melton LD. Woolliness in stone fruits. ASEAN Food Journal 1992;7(1):13-6.

[3] De Smedt V, Pauwels E, De Baerdemaeker J, Nicolaï B. Microscopic observation of mealiness in apples: a quantative approach. Postharvest Biology and Technology 1998 (in press).

[4] Ortiz C, Barreiro P, Ruiz-Altisent M, Riquelme F. Assessment of textural disorders in peaches (Cv. Maycrest) during cold storage by instrumental means. Instrumental assessment of mealiness (II). Postharvest Biology Technology 1998 (submitted).

[5] Barreiro P, Ortiz C, Ruiz-Altisent M, Recasens I, Asensio MA Mealiness assessment in apples comparison between human and instrumental procedures. From Sensors to Decision Support System in Agriculture, Food-industry and Environment. CD ROM Proceedings of Sensoral'98, Montpellier, France, February 23-27, 1998 Cemagref, Agro, INRA, 1998.

[6] Chen P, McCarthy MJ, Kauten R. NMR for internal quality evaluation of fruits and vegetables. Transactions of the ASAE 1989;32: 1747-53.

[7] Wang SY, Wang PC, Faust M. Non-Destructive Detection of Watercore in apple with Nuclear Magnetic Resonance Imaging. Scientia Hortculturae 1989;35:224-34.

[8] Clark CJ, Forbes SK. Nuclear Magnetic Resonance Imaging of the development of chilling injury in 'Fuyu' persimmon (Diospynus Kaki). New Zealand J of Crop and Horticultural Sci 1994;22:209-15.

[9] Zion B. Detection of Internal Tissue Breakdown in Galia Melons by Magnetic Resonance Methods. Annual Report of the Institute of Agricultural Engineering The Volcani Centre. 1994.

[10] Barreiro P, Ruiz-Altisent M, Ruiz-Cabello J, Fernández-Valle ME. Mealiness assessment in apples using MRI Techniques. Submitted to Magnetic Resonance Imaging. 1998. 